\title{
PENGEMB ANGAN MEDIA AJAR GRAFIS KOMPUTER MATERI WPAP DALAM BENTUK E-BOOK DAN VIDEO TUTORIAL BAGI MAHASISWA SENI RUPA
}

\author{
Gamal Kartono ${ }^{1 *}$, Mesra ${ }^{2 *}$, Adek Cerah Kurnia Azis ${ }^{3 *}$ \\ Program Studi Pendidikan Seni Rupa Jurusan Seni Rupa Fakultas Bahasa dan Seni \\ Universitas Negeri Medan \\ Jl. Willem Iskandar Pasar V Medan Estate, Kec, Percut Sei Tuan, Kab. Deli Serdang, Kode Pos 20371 \\ Sumatera Utara. Indonesia \\ Email: gmalkart@gmail.com
}

\begin{abstract}
Abstrak
Adapun tujuan dari penelitian ini yaitu; 1). Meningkatkan minat dan hasil belajar mahasis wa Seni Rupa dalam membuat tugas materi WPAP pada Mata Kuliah Grafis Komputer, 2). Memaparkan validasi, praktikalitas, dan efektivitas modul dan video pada Mata Kuliah Grafis Komputer, dan 3). Menghasilkan sebuah publikasi ilmiah dalam prosiding Seminar Internasional. Modul dan video tutorial pembelajaran Mata Kuliah Grafis Komputer pada penelitian ini diperoleh bahwa tingkat pencapaian minat mahas is wa berada pada $95,23 \%$ dimana dari 42 orang mahasis wa hanya 1 (satu) orang mahasiswa saja yang tidak lulus dalam perkuliahan ini yaitu berada pada 4,78\% saja. Selanjutnya validitas modul dan video berada pada pencapaian $71,25 \%$ berada pada kategori valid, kemudian untuk nilai praktikalitas modul dan video berada pada pencapaian 69\% dapat dikatakan cukup praktis dan mampu meningkatkan minat pengguna dalamproses pembelajara pada Mata Kuliah Grafis Komputer, dan berada pada $84 \%$ keefektivitasan modul dan video, hal ini dapat dikatakan bahwa modul dan video sangat efektif selama proses pembelajaran pada Mata Kuliah Grafis Komputer. Diharapkan moduldan video tutorial hasil penelitian ini dapat terus meningkatkan minat dan has il belajar mahasiswa dalammeng ambil Mata Kuliah Grafis Komputer, namun diharapkanjuga untuk Mata Kuliah lainnyaada penemuan baru yang dapat meningkatkan minat dan hasil mahasis wa baik itu dalam bentuk modul, video, dan lain sebagainya, yang tujuan utamanya untuk meningkatkan minat dan hasil belajar mahasiswa Seni Rupa tentunya.
\end{abstract}

Kata Kunci: minat belajar, hasil belajar, WPAP.

\begin{abstract}
The purpose of this study are; 1). Increase the interest and learning outcomes of Fine Arts students in making WPAP assignments in Computer Graphic Courses, 2). Describe the validation, practicality, and learning modules and videos on Computer Graphic Courses, and 3). Produce scientific publications in International Seminars. Modules and video tutorials for learning Computer Graphic Courses in this study were obtained by students at the $95.23 \%$ level where of the 42 students only 1 (one) student could not be obtained in this lecture while at $4.78 \%$. Furthermore the validity of the module and videos according to the achievement of $71.25 \%$ according to the valid category, then for the practicality value of modules and videos in accordance with the achievement of 69\% can be accepted quite practical and able to increase user interest in the process of spending on Computer Graphic Courses, and depends on $84 \%$ effectiveness modules and videos, this can be requested modules and videos that are very effective during the learning process in the Computer Graphics Course. It is hoped that the modules and video tutorials of the results of this study can continue to increase students' interest and learning outcomes in taking Computer Graphic Courses, but it is also hoped that for other courses there arenew discoveries that can increase student interest and results in the form of modules, videos, etc. etc., whose purpose is to increase student interest and learning outcomes.
\end{abstract}

Keywords: learning interest, learning outcomes, WPAP

\section{PENDAHULUAN}

Minat dan hasil belajar merupakan dua halyang s aling berkorelasi satu s ama lainnya, dimana sebuah minat belajar yang tinggi berpengaruh terhadap hasil belajar yang tinggi pula tentunya. Minat belajar yang kurang, maka akan berpengaruh kepada hasil belajar yang kurang pula, namun sebaliknya jika seseorang memiliki minat belajar yang tinggi, tentunya hasil 
belajarnyapun akan menjadi lebih baik jika dibandingkan dengan ses eorang yang memiliki minat belajar yang rendah. Banyak hal yang dapat dilakukan untuk meningkatkan minat ters ebut, khususnya bagi mahasiswa Jurusan Seni Rupa Fakultas Bahasa dan Seni (FBS) Univers itas Negeri Medan (Unimed), s alah satunyadengan mengembangkan media pembelajaran. Seiring dengan berkembangnya zaman ke era-milenial sekarang ini, berbedanya kebutuhan antara generasi sebelumnya dengan generasi "now" yang sering diistilahkan saat ini. Generasi yang tidak bisa lepas dari gadget, smartphone, smartwatch, dan aplikasi pendukungnya seperti Facebook (FB), WhatsApp (WA), youtube, dan lain sebagainya, hal ini tidak bis a dilepaskan dari kehidupan generani zaman "now", generasi milenial yang ada di kehidupan ini, teriris di dalamnya dari kalangan mahasiswa.

Kehidupan mahasiswa tidak pernah lepas dari apa yang dis ebut task, setiapkali pertemuan dengan dosen per-Mata Kuliah selalu ada tugas-tugas yang harus diseles aikan oleh mahasiswa ters ebut, secara umum mahasiswa tidak lepas dari apa yang dis ebut dengan kurikulum "Kerangka Kualifikasi Nasional Indonesia (KKNI). KKNI merupakan kerangka penjenjangan kualifikasi yang dapat meyandingkan, menyetarakan, dan menginteraksikan capaian pembelajaran dari jalur pendidikan nonformal, pendidikan informal, dan/atau pengalaman kerja ke dalam jenis dan jenjang pendidikan tinggi(Permen RI, 2013:2). Khusus KKNI yang ada di Unimed lebih menekankan kepada 6 (enam) penugasan. Penugas an tersebut yaitu: Tugas Rutin disebutjuga dengan TR, Critical Book Report atau CBR, Critical Research/Jurnal Review disebut juga dengan CJR, Mini Riset atau MR, Rekayasa Ide atau disebut juga dengan RI, dan terakhir Projek" (Azis, 2018:01), dengan banyaknya tugas yang harus dikerjakan oleh mahasiswa Unimed khususnya mahasiswa Seni Rupa, maka perlu diberi stimulus yang tinggiuntuk dapat mengerjakan tugas tersebut dengan baik dan benar, meningkatkan minat dalam mengerjakan tugas sehingga mendapatkan hasil belajar yang baik nantinya.

Banyakhalyang dapat meningkatkan minat seorang mahasiswa dalam mengerjakan tugas-tugas yang diberikan oleh seorang dosen per-Mata Kuliahnya, salah satu diantaranya media ajar yang menarik. Dilihat dari media yang dapat meningkatkan minat seorang mahasis wa untuk mendapatkan hasil belajar yang lebih baik, khususnya bagi mahasiswa Seni Rupa, salah satu stimulus yang dapat dilakukan yakninya dengan membuat e-book ber-International Standard Book Number (ISBN) dan video tutorial berbasis e-learning untuk materi ajar Wedha 's Pop Art Potrait (WPAP) pada Mata Kuliah Grafis Komputer, yang dapat diakses, dibaca, ditonton, dan dipelajari oleh mahasiswa Seni Rupa melalui gadget, smartphone, smartwatch mereka masing-masing. Mahasiswa dapat menyimpan, men-share materi WPAP tersebut pada aplikasi Facebook (FB), WhatsApp (WA), youtube, e-mail, dan lain sebagainya, yang ada pada Handphone (HP) Android yang dimiliki oleh mahasiswa tersebut, kegiatan ini dapat dilakukan oleh mahasiswa tersebut diseluruh dunia manapun asalkan ditempat tersebut terhubung dengan network internet.

\section{KAJIAN TEORI}

\section{Media Ajar}

Banyak cara yang dapat dilakukan untuk meningkatkan minat dan hasil belajar ses eorang, salah satunya yaitu media ajar, di sini media ajar dapat dikembangkan menjadi menarik lagi yang sesuai dengan kebutuhan zaman now tentunya. Menurut Arief (1986) media pembelajaran adalah segala sesuatu yang dapat digunakan untuk menyalurkan pesan dari pengirim ke penerima, sumber informasi penerima sumber informasi sehingga dapat merangsang pikiran, perasaan, perhatian, dan minat seseorang sehingga terjadi proses belajar yang diharapkan. Dalam pembelajaran (instructional), sumber informasi adalah dosen, guru, instruktur, peserta didik, bahan bacaan, media ajar, dan sebagainya. "Media pengajaran merupakan wadah dan penyalur pesan dari sumber pesan, dalam hal ini dosen, kepada penerima pesan, dalam hal ini mahasiswa" (Rusdi, 2007:4).

Bertolak dari pendapat di atas Mahnun (2012:28) mengungkapkan bahwa "media pengajaran merupakan kebutuhan yang tidak dapat dielakukan dalam rangka menyukseskan program belajar siswa agar dapat tercapai perubahan tingkah laku yang diharapkan. Konsekuensinya, guru hendaknya memiliki peran dalam memilih media yang tepat dan melakukan pemilihan itu berdas arkan teknik dan langkah-langkah yang benar.

Berdasarkan beberapa penjelasan di atas maka dapat disimpulkan bahwa media merupakan segala hal yang dapat digunakan untuk menyalurkan pesan, informasi, knowledge, dan lain sebagainya, yang disampaikan oleh seorang dosen kepadamahasis wadengan inovasi media atau penyampaian yang lebih menarik sehingga dapat mens timulus keinginan belajar mahas is wa lebih tinggi lagi. Namun fenomena di lapanagan banyak guru yang tidak melakukan dan memahami langkah- 
langkah pemilihan media tersebut secara baik dalam pembelajaran, dengan demikian banyak guru yang masih berpusat pada dirinya atau papan tulis sebagi satu-satunya media dan sumber belajar. Bila fenomena ini dibiarkan maka ada kemungkinan pendidikan akan kurang bermutu, dan akan menghasilkan output yang verbalisme. Oleh karena itu tulisan ini mencoba mengangkat tentang pemilihan media.

\section{Grafis Komputer}

Seiring dengan berkembangnya zaman banyak perubahan yang terjadidalam dunia pendidikan, salah satunya perubahan media ajar dari konvensional berubah ke digital, pengerjaan digital tak lebas dengan apa y ang disebut dengan komputer sebuah mes in yang mempermudah suatu pekerjaan seseorang, di sini akan diulas secara tajam apa itu Grafis Komputer. Definisi Grafis Komputer suatu bidang ilmu yang mempelajari bagaimana "membangun" grafik (gambar) baik $2 D$ maupun $3 D$ yang kelihatan nyata menggunakan komputer. Suatu proses pembuatan, penyimpanan dan manipulasi model dan citra. Model berasal dari beberapabidang seperti fisik, matematik, artistik dan bahkan abstrak. Grafik Komputer ditemukan tahun 1960 oleh "Willian Fetter": Pembentukan desain model cockpit (Boeing) dengan menggunakan pen ploter dan referensi model tubuh manusia 3 Dimensi (Khaliesh, 2010:2). Dalam dunia kesenirupaan Grafis Komputer ini dijadikan sebuah Mata Kuliah yang wajib dipelajari, dipahami, dan dikuasai. Berbagai macam penamaan pada Mata Kuliah ini, ada beberapa kampus menyebutnya Komputer Grafis, Desain Grafis, Grafik Komputer, dan lain sebagainya. Khusus untukJurusan Seni Rupa Unimed, penyebutan dengan istilah Grafis Komputer, seorang mahasiswa Seni Rupa Unimed wajib mengambil mata kuliah ini.

\section{Wedha's Pop Art Potrait (WPA)}

Salah satu materi tugas perkuliahan yang ada pada Mata Kuliah Grafis Komputer di Jurusan Seni Rupa Unimed adalah membuat Tugas Rutin (TR) dan Projek WPAP. WPAP atau Wedha's Pop Art Potrait adalah suatu gugus seni ilustrasi potret wajah yang bersaling silang secara geometri dengan penggunaan kontradiksi warna-warna khusus. Dimensi dari gambar yang ditrace (gambar ulang dengan acuan) tidak berubah, sehingga penampakan akhir dari objek yang ditransformasi jelas dan menyerupai as liya sehingga mudah dikenali. Teknik melukis ini ditemukan oleh Wedha Abdul Rasyid, seorang seniman grafis asal Pekalongan, Jawa Tengah, pada tahun 1990. Awal kepopuleran WPAP adalah ketika digunakan untuk mengilustrasikan cerita-cerita karya Arswendo
Gorga : Jurnal Seni Rupa

Volume 09 Nomor 01 Januari-Juni 2020

p-ISSN: 2301-5942 | e-ISSN: 2580-2380

Atmowiloto dan Himan Hariwijaya di majalah "Hai" (WPAP, 2015). Berikut contoh karya WPAP.

\section{Minat}

Minat merupakan keinginan untuk dapat memiliki sesuatu, dorongan yang ada dalam diri, mencapai sebuah yang diminati. Menurut Jersild dan Tasch dalam Wayan, (1986:229) bahwa minat atau interest menyangkut aktifitas-aktifitas yang dipilih secara bebas oleh individu. Seseorang akan memilih yang diinginkannya sesuai deng an kehendak hatinya tanpa ada paksaan dari siapapun. Kehendak yang timbul ters ebut menarik perhatian untuk dapat memiliki atau melakukannya.

MenurutSumadi(1993:16) mengemukakan "halyang menarik perhatian adalah hal yang dari konteksnya" atau kalau dikatakan secara sederhana "hal yang menarik perhatian adalah hal yang lain dari lainlainnya". Kemudian Slameto (1995:181) manjelaskan usaha pencapaian minat yaitu dapat memakai insentif dalam usaha pencapaian tujuan pengajaran. Insentif merupakan alat yang dipakai untuk membujuk seseorang agar melakukan sesuatu yang pemberian insentif akan mambangkitkan motivasi siswa dan mungkin minat terhadap bahan yang diajarkan akan muncul. Jadi, minat pada dasarnya adalah penerimaan akan suatu hubungan antara diri sendiri dengan sesuatu di luar diri (Slameto, 1995:180).

Minat ini merupakan potensi yang dimiliki individu, merupakan sesuatu yang perlu s ekali digali agar dapat diaplikasikan dengan tepat sesuai dengan bidangnya. Hal ini penting sekali diterapkan khususnya dalam rangka penentuan karir, untuk mengetahui kekuatan kelemahan kemampuan individu mahasiswa agar mahas is wa mampu memahami dirinya (pemahaman diri) terutama minat-minatnya, dengan mengetahui secara jelas kekuatan kelemahan dirinya sendiri, individu akan mampu membuat perencanaan dan keputusan karirnya di masa depan. Selanjutnya Azis, (2010:7) mengungkapkan bahwa minat adalah suatu rasa lebih suka terhadap sesuatu yang timbul dari dalam diri (interen) dan pengaruh dari luar diri (eksteren). Minat ini timbul tanpa ada paksaan dari siapapun, merupakan kehendak dari diri sendiri, hal yang diminati merupakan sesuatu yang menarik untuk dimiliki atau dilakukan untuk karir masa depan.

Berdasarkan uraian tentang minat di atas maka dapat disimpulkan bahwa minat adalah keinginan yang timbul dari dalam diri (internal) seseorang akan ketertarikan terhadap sesuatu yang interest berasal dari luar diri (eksternal), menimbulkan keinginan 
untuk mendekati, mempelajari, menyentuh, dan lain sebagainya lebih dekat lagi.

\section{Hasil Belajar}

Berikut ini penjelasan tentang pendefinisian hasil belajar, Mesra (2016:308) mengungkapkan bahwa hasil belajar adalah "kemampuan-kemampuan yang dimiliki peserta didik setelah menerima pengalaman belajar yang meliputi seluruh mental, ranah-ranah kognitif, afektif, dan psikomotor setelah mengikui proses pembelajaran", Winkel (1983) prestasi belajar adalah hasil suatu penilaian di bidang pengetahuan, keterampilan dan sikap sebagai hasil belajar yang dinyatakan dalam bentuk nilai. Menurut Sudjana (1987) prestasi belajar adalah kemampuan yang dimiliki oleh siswa setelah menerima pengalaman belajar, dengan demikian prestasi belajar diartikan sebagai suatu hasil atas kecakapan atau kemampuan seseorang pada bidang tertentu dalam mencapai tingkat kedewasaan yang langsung dapat diukur dengan test. Prestasi belajar merupakan penguasaan pengetahuan atau keterampilan yang dikembangkan melalui mata pelajaran, lazimnya ditunjukkan dengan nilai tes atau angka nilai yang diberikan oleh seorang dosen (Alwi, 2002:25). Berdasarkan uraian di atas maka dapat disimpulkan bahawa hasil belajar merupan nilai yang diperoleh seorang peserta didik setelah mengikuti pembelajaran, melaksanakan test, dalam bentuk angka atau huruf.

\section{METODE PENELITIAN}

Jenis penelitian yang akan dilakukan ini masuk ke dalam penelitian pengembangan, di mana pada penelitian ini akan membuat sebuah produk baru untuk mendukung sistem pembelajaran. Pengembangan dilakukan pada materi ajar WPAP pada Mata Kuliah Grafis Komputer, dengan media berupa e-book Mata Kuliah Grafis Komputer dan video tutorial ber-basis e-learning tujuannya untuk meningkatkan hasil belajar mahas is wa Seni Rupa.

Penelitian ini menggunakan model $4 D$ (four- $D$ models). Menurut Thiangarajan (1974:7) pengembangan model four-D terdiri dari 4 (empat) tahapan: 1). Pendefenisian (define); 2). Perancangan (design); 3). Pengembangan (develop); dan 4). Penyebaran (dessiminate). Penelitian ini hanya sampai pada tahap pengembangan (develop) yaitu tahap 3 (tiga).

\section{HASIL DAN PEMBAHASAN 1.Hasil}

\section{1). Hasil Penilaian Validator}

Gorga : Jurnal Seni Rupa

Volume 09 Nomor 01 Januari-Juni 2020

p-ISSN: 2301-5942 | e-ISSN: 2580-2380

Tabel 1. Hasil Penilaian Validator

\begin{tabular}{|l|l|c|c|}
\hline No & Variabel & Pencapaian (\%) & Kategori \\
\hline 1. & Isi Modul & 70 & Valid \\
\hline 2. & Konstruksi & 71 & Valid \\
\hline 3. & Bahasa & 69 & Valid \\
\hline 4. & Tampilan Modul & 75 & Valid \\
\hline \multicolumn{2}{|c|}{ Rata-rata } & $\mathbf{7 1 , 2 5}$ & Valid \\
\hline
\end{tabular}

Hasil analis is skor penilaian validator tersebut di atas, yang terdiri dari 4 (empat) variabel menjelaskan bahwa, 1) Isi modul berada pada pencapaian $\mathbf{7 0 \%}$ masuk kedalam kategori valid, 2) konstruksi berada pada pencapaian $\mathbf{7 1 \%}$, pecapaian ini berada ke dalam kategori valid, 3) variabel Bahasa mencapai persentase yaitu $69 \%$ dikategorikan valid, dan 4) tampilan modul berada pada pencapaian $\mathbf{7 5 \%}$ dan dapat dikategorikan valid juga. Berdas arka ke-empat variabel di atas, maka dapat dirata-ratakan apa persentase $\mathbf{7 1 , 2 5 \%}$ berada pada kategori valid. Perbandingan derajat pencapaian hasil validasi modul pada masing-masing variabel yang telah dilakukan penilaian oleh validator dapat dilihat pada gambar 1 , berikut ini:

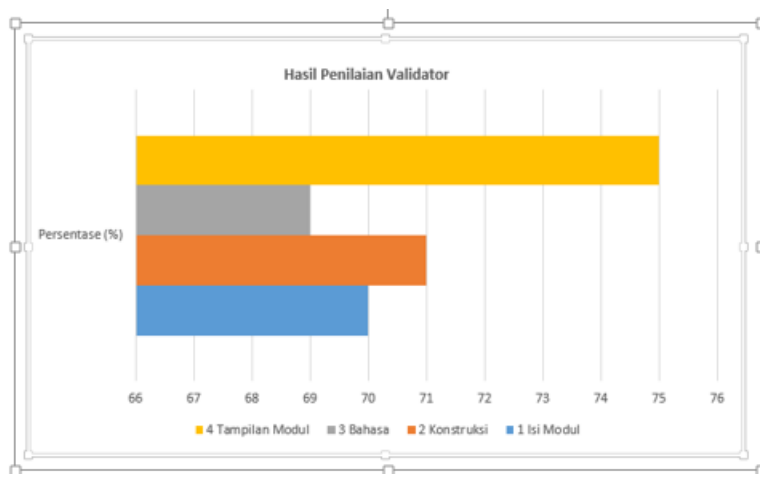

Gambar 1. Hasil Penilaian Validator

\section{2). Hasil Praktikalitas Mahasis wa}

Tabel 2. Hasil Praktikalitas Mahasiswa

\begin{tabular}{|l|l|c|c|}
\hline No & \multicolumn{1}{|c|}{ Variabel } & Pencapaian (\%) & Kategori \\
\hline 1. & Modul $(\boldsymbol{E}$-book) & $\mathbf{6 7 , 6 7}$ & Cukup Praktis \\
\hline a. & Ukuran Modul & 67 & Cukup Praktis \\
\hline b. & $\begin{array}{l}\text { Desain Sampul } \\
\text { Modul (Kover) }\end{array}$ & 68 & Cukup Praktis \\
\hline c. & Desain Isi Modul & 68 & Cukup Praktis \\
\hline 2. & Video Tutorial & $\mathbf{7 0 , 3 3}$ & Cukup Praktis \\
\hline a. & Tampilan & 69 & Cukup Praktis \\
\hline b. & Pengoperasian & 72 & Cukup Praktis \\
\hline c. & Kemanfaatan & 70 & Cukup Praktis \\
\hline & Rata-rata & $\mathbf{6 9}$ & Cukup Praktis \\
\hline
\end{tabular}

Hasil analis is data penilaian dari mahas isa kelas A dan B Reguler Program Studi Pendidikan Seni Rupa, Jurusan Seni Rupa, Fakultas Bahasa dan Seni, Universitas Negeri Medan yang sekaligus menjadi objek uji coba modul peningkatan minat mahasis wa dalam membuat 6 (enam) penugasan Kerangka Kualifikas Nasional Indonesia (KKNI) pada Mata Kuliah Grafis Komputer terdapat 4 (empat) variabel, 
yaitu 1). Modul (e-book) berada pada persentase $\mathbf{6 7 , 6 7 \%}$ berada pada kategori cukup praktis, a) ukuran modul berada pada pencapaian $67 \%$ berada pada kategori cukupprak tis, b) desain sampul modul (Kover) berada pada pencapaian $68 \%$ masih berada pada kategori cukup praktis, dan c) desain isi modul berada pada pencapaian $\mathbf{6 8 \%}$ berada pada kategori cukup praktis. 2). Video tutorial berada pada persentase $\mathbf{7 0 , 3 3 \%}$ berada pada kategori cukup praktis, a). Tampilan video tutorial berada pada persentase $69 \%$ masuk ke dalam kategori cukup praktis, b). pengoperasian video tutorial masuk ke dalam $72 \%$ berada pada kategori cukup praktis, dan c). kebermanfaatan video tutorial berada pada persentase $70 \%$ masuk ke dalam kategori cukup praktis juga. Secara keseluruhan dapat dirata-ratakan ke dalam persentase $69 \%$ dan masuk ke dalam kategoricukup praktis. Untuk lebih jelas pencapian praktikalitas moduloleh mahas iswa dapat dilihat pada gambar 2, berikut ini:

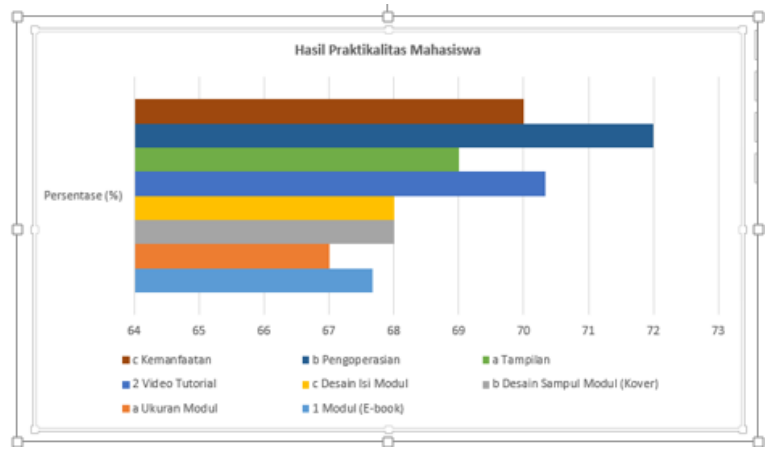

Gambar 2. Hasil Praktikalitas Mahasiswa

\section{3). Hasil Persentase Pencapaian Aktivitas Mahasiswa}

Tabel 3. Hasil Persentase Pencapaian Aktivitas Mahasiswa

\begin{tabular}{|c|l|l|l|}
\hline No. & \multicolumn{1}{|c|}{$\begin{array}{c}\text { Kategori Aktivitas } \\
\text { Mahasiswa }\end{array}$} & $\begin{array}{c}\text { Persentase } \\
(\boldsymbol{\%})\end{array}$ & Kriteria \\
\hline 1. & $\begin{array}{l}\text { Membaca modul dan } \\
\text { mengerjakan latihan }\end{array}$ & 100 & $\begin{array}{l}\text { Aktif } \\
\text { Sekali }\end{array}$ \\
\hline 2. & $\begin{array}{l}\text { Memberikan pertanyaan } \\
\text { kepada dosen yang } \\
\text { bersangkutan disaat } \\
\text { mengikuti proses belajar } \\
\text { mengajar }\end{array}$ & 58,40 & $\begin{array}{l}\text { Cukup } \\
\text { Aktif }\end{array}$ \\
\hline 3. & $\begin{array}{l}\text { Berikan jawaban atas semua } \\
\text { pertanyaan yang diberikan } \\
\text { oleh dosen dan teman sejawat }\end{array}$ & 62,77 & $\begin{array}{l}\text { Cukup } \\
\text { Aktif }\end{array}$ \\
\hline 4. & $\begin{array}{l}\text { Mengumpulkan tugas yang } \\
\text { diberikan oleh dosen. }\end{array}$ & 100 & $\begin{array}{l}\text { Aktif } \\
\text { Sekali }\end{array}$ \\
\hline \multicolumn{2}{|r|}{ Rata-rata Secara Keseluruhan } & 80,29 & Aktif \\
\hline
\end{tabular}

Berdas arkan hasil analisis aktivitas mahasis wa selama proses pembelajaran dengan tingkat pencapaian persentase $80,29 \%$ masuk ke dalam kategori mahasis wa aktif dan bisa dikatakan sudah mendekati aktif s ekali. Untuk melihat perbandingan hal ters ebut di atas dapat dilihat pada gambar 3, berikut ini:

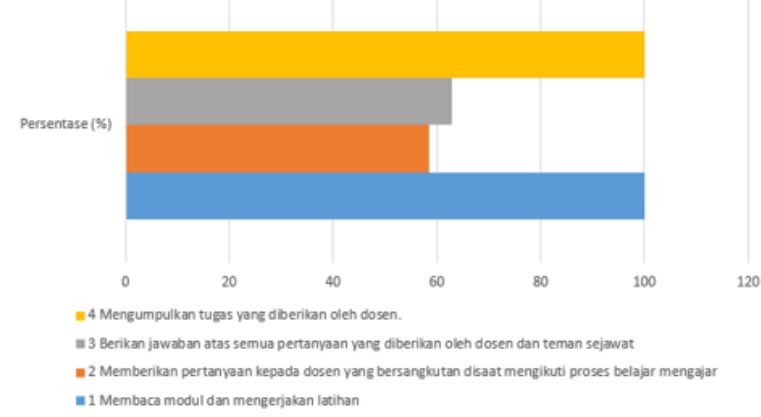

Gambar 3. Aktivitas Mahasiswa Berdasarkan Pengamat

\section{Pembahas an}

Analisis skor penilaian validator pengkategorian modul masuk ke dalam kategori valid, dimana hasil rata-rata dari variabel isi modul, konstruksi, bahasa, dan tampilan modul berada pada persentase $71,25 \%$. Hal ini menunjukkan modulvalid untuk meningkatkan minat pengguna.

Tampilan modulyang menarik mampu meningkatkan minatnya mahasiswa dalam belajar berada pada pencapaian 75\% dikateg orikan Praktis. Uraian is i pada moduldis us un secara sistematis, hal ini memudahkan pengguna dalam memahami modul. Modul dirumuskan dalam satu unit pembelajaran yang diawali dengan penyanyian materi dan evaluasi. Penyajian modul sesuai dengan tingkat kemampuan mahas is wa. Menurut Depdiknas (2008a:3-5) sebuah modul dikatakan baik dan mudah dipahami siswa jika materi dalam satu unit yang utuh sesuai dengan kemampuan pengguna (SelfContained).

Kemudahan bagi pengguna (Learnability) modul dan video yaitu dosen sebagai pembimbing dalam proses pembelajaran dengan nilai $80 \%$ berada pada kategori praktis bagi pengguna. Dimana modul dan video mudah digunakan sehingga mahas is wa tertarik dan meningkatkan minat mereka dalam menggunakan modul dan video.

Daya guna modul dan video bagi mahasiswa (Efficiency) deng an pencapaian nilai 86,67\% masuk ke dalam kategori praktis. Modul dapat membantu mahas is wa dalam menerangkan konsep. Diharapkan juga mampu membantu dosen mengarahkan mahasiswa dalam proses pembelajaran. "salah satu dari tujuan modul adalah memperjelas dan mempermudah penyajian pesan agar tidak terlalu bersifat verbal (Depdiknas, 2008b:5-6). Kepraktis an dan efektifitas waktu (Effectiveness of Time) berada pada kategori praktis dengan nilai pencapaian $84 \%$. 
Moduldikembangkan secara praktis digunakan oleh dosen untuk membimbing mahas is wa dalam proses pembelajaran. Dosen dapat memanfaatkan waktu yang minimal dengan hasil belajar yang maksimal. Menurut Depdiknas (2008b:5) modul yang baik dapat mengatasi keterbatasan waktu, ruang, dan daya indera, bagi guru/pembimbing dalam proses pembelajaran.

Hasil evaluasi belajar mahasiswa dapat dinyatakan lulus sebanyak 42 orang dan 1 orang mahasiswa dinyatakan tidak lulus. Persentase mahas is wa yang lulus $95,23 \%$ dan 4,78\% persentase yang tidak lulus. Tujuan evaluasi untuk menentukan apakan mahasiswa yang diajar sudah memiliki kompetensi yang telah ditetapkan sehingga layak diberikan materi pembelajaran berikutnya.

Kepraktisan modul membuktikan bahwa, 42 orang mahas is wa yang menggunakan modul dalam proses pembelajaran, $95.23 \%$ mahasiswa dinyatakan tuntas Selanjutnya, berdasarkan pengamatan yang diamati oleh satu orang pen gamat, umumnya mahas is wa aktif dalam proses pembelajaran. Hal ini menunjukan bahwa modul praktis, efektif, dan dapat meningkatkan minat mahasis wa dalam proses pembelajaran pada Mata Kuliah Grafis Komputer.

\section{KESIMPULAN DAN SARAN \\ 1.Kesimpulan}

Berdas arkan uraian data dan pembahasan di atas dapat disimpulkan sebagai berikut: 1). Telah dihasilkan moduldan video Mata Kuliah Grafis Komputer untuk peningkatan minat mahasiswa Jurusan Seni Rupa dalam membuat 6 (enam) penugasan Kerangka Kualifikasi Nasional Indonesia (KKNI) Revitalis asi 2018, dan 2). Nilai validitas modul berada pada pencapaian $71,25 \%$ berada pada kategori valid. Nilai praktikalitas moduldan video oleh mahasiswa berada pada tingkat pencapaian $69 \%$ dapat dikategorikan cukup praktis dan mampu meningkatkan minat pengguna dalam proses pembelajaran.

\section{Saran}

Diharapkan peneliti-peneliti berikutnya untuk mengembangkan modul berbas is karakter (soft skill) yang lebih ditekankan kepada attitude peningkatan minat dan hasil belajar dalam proses pembelajaran, khususnya di Jurusan Seni Rupa, Fakultas Bahasa dan Seni Universitas Negeri Medan.

nya wawas an dan kemampuan tentang menggambar sketsa dan perspektif dapat ditambah lagi pada ranah pembelajaran seni budaya di sekolah, dengan tujuan agar kemampuan menggambar sketsa dan perspektif yang dimiliki bisa memberikan masukan yang lebih
Gorga : Jurnal Seni Rupa

Volume 09 Nomor 01 Januari-Juni 2020

p-ISSN: 2301-5942 | e-ISSN: 2580-2380

besar dalam menunjang kemampuan siswa untuk menggambar bentuk yang lebih baik.

\section{DAFTAR RUJUKAN}

Alwi Hasan dkk. (2002). Kamus Besar Bahasa Indonesia. Jakarta: Balai Pustaka.

Arief S. Sadiman,dkk. (1986). Seri Pustaka Teknologi Pendidikan No.6 Media Pendidikan.

Pengertian, Pengembangan, dan

Pemanfaatannya. Jakarta: CV Rajawali.

Azis, A. C. K. (2018). Pengembangan Materi Ajar Komik pada Mata Kuliah Menggambar Ilustrasi untuk Meningkatkan Motivasi dan Hasil Belajar Mahasiswa Seni Rupa dalam Membuat Penugasan KKNI Revitalisasi 2018. Medan: LPM Unimed.

Khaliesh, Hamdil. (2010). Pengenalan Komputer Grafis. Pontianak: Universitas Tanjung Pura.

Mahnun, Nunu. (2012). Media Pembelajaran (Kajian terhadap Langkah-Langkah Media dan Implementasinya dalam Pembelajaran). Jurnal Pemikiran Islam, 37(01), 28.

Mesra, M., Azis, A. C. K., \& Astuti, W. W. (2016). Kontribusi Motivasi Belajar Dan Lingkungan Tempat Tinggal Terhadap Hasil Belajar Mahasiswa Jurusan Seni Rupa Universitas Negeri Medan. Jurnal Bahas Unimed, 27(3), 302-319.

Permen RI. (2013). Tentang Kerangka Kualifikasi Nasional Indoneia (KKNI). Jakarta:

Rasyid, Wedha Abdul. (2018). Wedha dan WPAP (Wedha's Pop Art Potrait). Jakarta: Elex Media Komputindo.

Rusdi Susilana \& Cepi Riyana. (2007). Media Pembelajaran Hakikat Pengembangan, Pemanfaatan, dan Penilaian. Bandung: Wacana Prima.

Slameto. (2003). Belajar dan Faktor-Faktor yang Mempengaruhinya. Jakarta: Rineka Cipta.

Sudjana, Nana. (1987). Dasar-Dasar Belajar Mengajar. Bandung: Sinar Baru.

Sumadi, Suryabrata. (2002). Pengertian Minat. Jakarta: Rineka Cipta.

Wayan, Nurkancana. (1986). Evaluasi Pendidikan. Surabaya: Usaha Nasional.

WPAP Community. (2015). WPAP atau Wedha's Pop Art Potrait. Diunduh pada26 Mei 2019 (Online). Di $\underline{\text { https://id.wikipedia.org/wiki/WPAP }}$ 